\title{
AUTOMATED DETECTION OF FAULTS AND FRACTURES IN WELL SEISMIC DATA IN THE CAMPOS BASIN
}

\author{
Frank Cenci Bulhões ${ }^{1}$, Renan de Jesus Melo ${ }^{1}$, Renata Lira Oliveira ${ }^{1}$, Gleidson Diniz Ferreira ${ }^{1} 1$ Petrobras - Petróleo
}

Brasileiro S.A.

Copyright 2021, SBGf - Sociedade Brasileira de Geofísica

This paper was prepared for presentation during the $17^{\text {th }}$ International Congress of the Brazilian Geophysical Society held in Rio de Janeiro, Brazil, 16-19 August 2021.

Contents of this paper were reviewed by the Technical Committee of the $17^{\text {th }}$ International Congress of the Brazilian Geophysical Society and do not necessarily represent any position of the SBGf, its officers or members. Electronic reproduction or storage of any part of this paper for commercial purposes without the written consent of the Brazilian Geophysical Society is prohibited.

\section{Abstract}

Vertical seismic profile (VSP) data is generally considered to be underutilized. Traditionally, VSP data is acquired to determine direct time-depth relationships and produce sections and images. Faults and fractures may be important to improve reservoirs exploitation as well as to monitor mechanical and hydraulic impact on reservoir rocks. This work presents a case study applied to an offshore seismic survey in the Campos Basin. A multioffset VSP data set is used as input in an automated fault and fracture detection workflow usually applied to conventional seismic data using coherence attributes. The automatic extraction of faults and fractures uses signal processing and interactive tools to reduce interpretation time compared to fully manual methods. Workflow's input is a volume of discontinuity or similarity extracted from VSP's amplitude, and the output is a volume of fault azimuths. In work carried out, the directions of faults and fractures detected from this workflow showed great correlation when compared to the interpretations in the wells. The attributes proved to be quite effective in improving the visualization of faults and fractures.

\section{Introduction}

The mapping of faults and fractures is essential, especially for gas reservoirs. In addition to the importance of defining migration routes, accumulations occur in the vicinity of regions with a higher density of fractures (Lira et al., 2018).

Fracture modeling is a multi-step multidisciplinary process that incorporates geological concepts and data interpretations from different sources. Among the inputs used in this process, we can highlight the following:

- Data based on field outcrops for parameterization of algorithms.

- Seismic interpretation of horizons (layers and faults) and generation of seismic attributes should guide the preferential orientation of fractures.

- Variation of seismic velocities in multi-azimuth data (Figure 1).
- Interpretation of faults and fractures in image profile data.

Compared to other fracture measurements, seismic data's main advantage is that long wavelengths are sensitive to the cumulative effects of a wide range of fracture scales. Large, more compatible fractures, which can significantly impact fluid flow, are likely to contribute more to the observed seismic anisotropy (Queen and Rizer 1990).

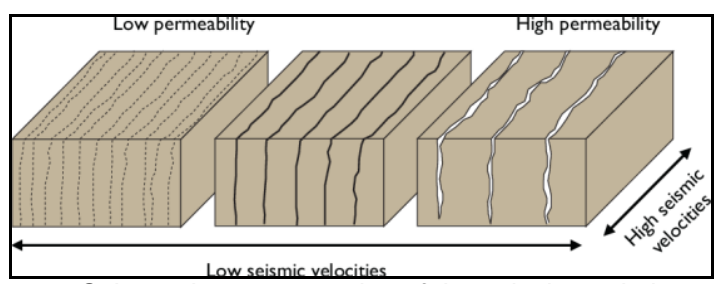

Figure 1: Schematic representation of the velocity variation as a function of the fracture direction.

Source: Baird et al. (2013).

The use of seismic attributes is fundamental in seismic interpretation, mainly to identify faults and fractures. According to Azevedo et al. (2009): "Seismic attributes are a way of describing and quantifying seismic signal content, providing alternative ways of visualizing seismic data that are normally presented in amplitudes."

The accuracy and quality of these seismic attributes are directly proportional to the seismic data's signal-to-noise ratio (Santosh et al., 2013). Data conditioning increases the visual identification of faults and fractures in seismic data and their attributes. Dip and azimuth volumes are the basis for volumetric curvature, coherence, amplitude gradients, seismic textures, and filters structurally oriented These attributes extracted from the seismic volume provide more robust estimates than those based only on horizons. The previous volumes mark fault shadows and velocity artifacts such as pull up and push down. (Marfurt et al., 2011) The noise distorts the image and makes detecting and interpreting geological features difficult, aiming to illuminate the geometry and the location of the various faults and fractures of major and minor scales.

\section{Seismic Coherence}

Coherence is a measure of similarity between waveforms or traces (Equation 1). The volume of coherence provides a quantitative estimate of discontinuities that may be related to the presence of stratigraphic faults and fractures or erosions/terminations and is an excellent tool for delimiting stratigraphic faults and contacts, allowing the rapid assessment of large volumes of data and the 
increase of stratigraphic information that is difficult to identify.

$$
\text { coherence }=\frac{\text { Energy of calculated coherence }}{\text { Energy of the input traces }}
$$

Coherence is a measure of similarity of the waveform compared to the adjacent lines, either in the direction of the inline or the crossline.

The coherence estimate is generally made along with the layered dive so that the geological discontinuities are detected as structural or stratigraphic interruptions and not related to the layered dive (Figure 2).
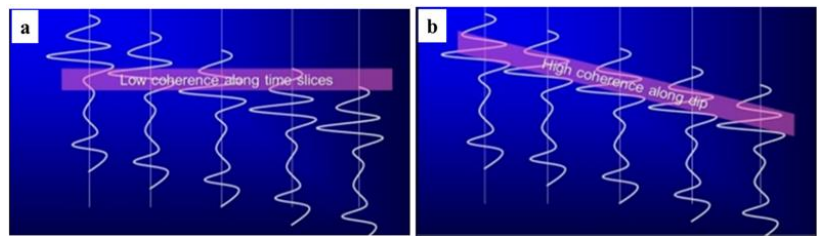

Figure 2: (a) Consistency is low across the time slice. (b) consistency is high throughout the dive.

Source: Marfurt et al. (2011).

\section{Automatic Extraction of Faults and Fractures}

Traditionally, faults and fractures are interpreted as discontinuities in seismic amplitude volumes. The automatic extraction of faults and fractures uses signal processing technology and interactive tools to decrease the interpretation time compared to fully manual methods. The input of this flow is a volume of coherence extracted from the amplitude, and the output is a volume of the relative probability of faults and fractures.

Interactive tools have been developed to assist the interpreter in this process. Hale and Emanuel (2002) published the results of the research focused on the automatic mesh that could be applied to the fault interpretation and Pedersen et al. (2003) described a semi-automatic process for extracting faults and fractures using "ant tracking" in a volume of discontinuity in fracture modeling.

Automatic Fault Extraction uses signal processing technology combined with steps with a set of interactive tools to allow the interpretation of automated and semiautomatic faults and fractures in less time and with less effort than completely manual methods (Dorn et al. 2005).

VSP

The vertical well seismic methodology (VSP - Vertical Seismic Profile) is generally considered to be underutilized. Traditionally, VSP data is acquired to determine direct time-depth relationships and produce sections and images.

The mapping and characterization of natural subsurface fractures are important to observe hydrocarbon reservoirs' development due to the great mechanical and hydraulic impact of the fractures on the reservoir rocks, especially gas. In addition to the importance of defining migration routes, accumulations occur in the vicinity of regions with a higher density of fractures. Horne (2003) discussed that VSP is a powerful tool in establishing anisotropy directions when vertical fractures and fracture systems cause anisotropy.

Walkaway survey data (Figure 3 ) is generally acquired to provide information of anisotropy and structural information, and intermediate data is often used to provide information on fracture directions. These displacement data sets contain an abundance of additional information, particularly on fractures, which are rarely explored but can be extracted through additional advanced processing.

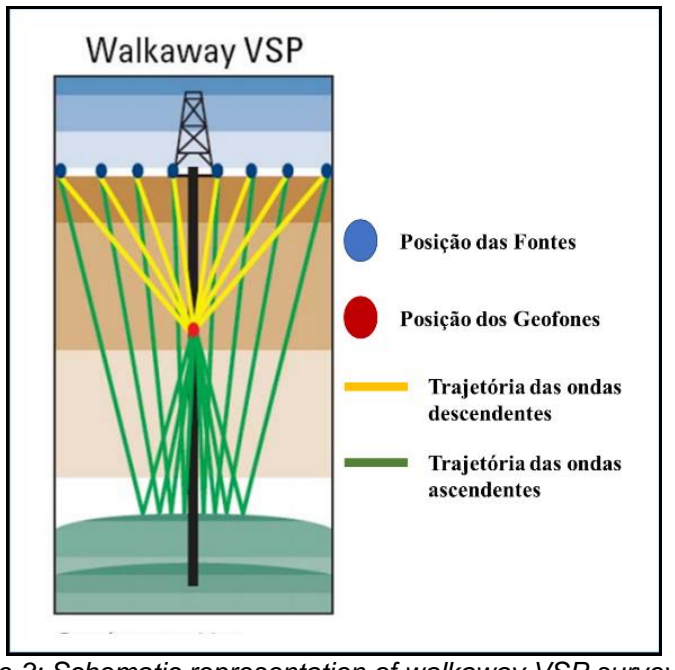

Figure 3: Schematic representation of walkaway VSP survey. Source: Modified from Campbel et al. (2005).

The VSP walkaround is a type of seismic data acquisition. Several sources on the surface are azimuth organized around a fixed position of the receiver in the well, keeping the source-receiver distance approximately constant. Walkaround VSPs are the most common well seismic techniques used to characterize fractured reservoirs with sub-vertical fractures, which have proven robust in simple geological surveys. As outlined in Figure 4, they have seismic sources along a circular path around the receivers (Horne 2003). The receptors are located in the fractured reservoirs so that the characterization is carried out through the transmission analysis (birefringence) of the descending shear waves converted not far above the reservoir.

In walkaround VSPs, the descending shear waves are generated above the fractured reservoir and analyzed along with the line and cross line components in all azimuths of origin. The transverse components' polarity should change in the symmetry planes of the fractured reservoir (planes parallel and perpendicular to the main fractures). It is expected that the ratio between the transversal energy of the $S$ wave and the radial energy of the $S$ wave will disappear along the direction of symmetry, where there is no division of the $S$ wave and only propagation of fast or slow shear waves (Figure 5). 


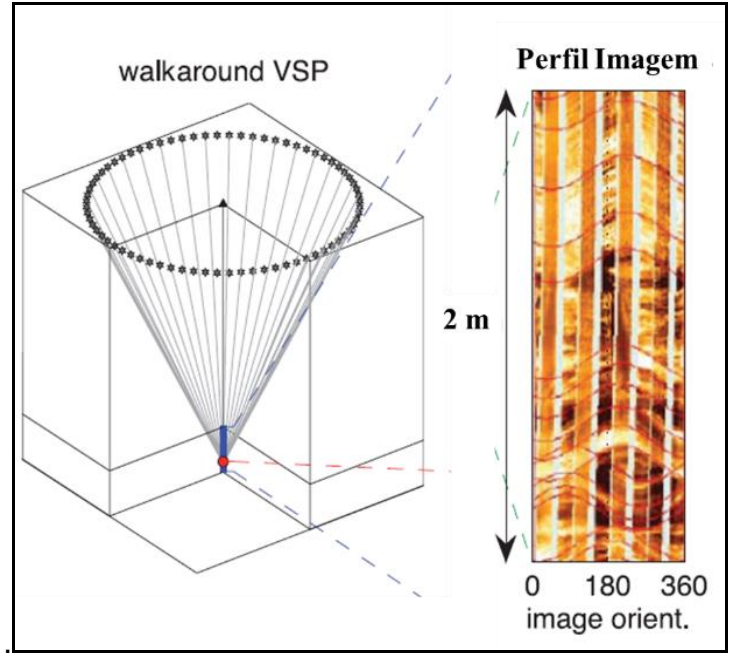

Figure 4: Schematic representation of a walkaround VSP survey and image profile.

Source: Modified by Prioul and Jocker (2009).

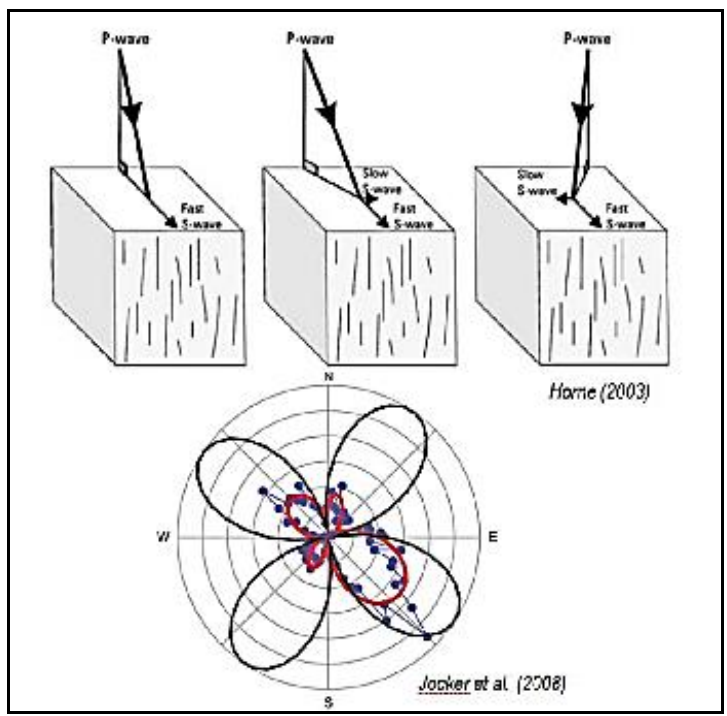

Figure 5: Representation of the $P$ wave incident in different directions and converted to $S$ in the set of fractures.

Source: Horne (2003) and Jocker et al. (2008).

The shear wave division analysis in the walkaround VSP interprets a maximum stress direction (or fracture direction) from variations in apparent amplitude and velocity.

In a flat and vertically fractured system, the Transversal / Radial amplitude ratio (T/R) should highlight high values, close to 1 , at $45^{\circ}$ of the fracture strike and normal directions. Low values, close to 0 , must be observed along the fracture strike and in normal directions because the shear wave does not split along these azimuths. They are determining the fracture directions in the VSP walkaround. Polarity flips are expected for the shear waves in the transverse components when the source moves through the planes of symmetry. The proportion of the $S$ wave energy (Transversal/Radial) must also disappear along with the directions of symmetry, where the division of the $S$ wave does not occur.

The VSP data were processed to obtain the radial and transverse shear components by the source's azimuthal location. Radial displacement is the displacement component of the horizontal wave field-aligned towards the source. The horizontal transverse offset is orthogonal to the radial direction, also in the horizontal plane. The relationship between transverse to radial displacement, hereinafter referred to as the $T / R$ ratio is a useful attribute. It can be shown as minimal when the sourcereceiver line is perpendicular or parallel to the fracture system.

\section{Materials and methods}

This work presents a case study in which a multi-offset VSP data set is used as input automated fault and fracture detection workflow. The study was applied to an offshore seismic survey in the Campos Basin.

Traditionally, faults and fractures are interpreted as discontinuities in seismic amplitude data Gersztenkorn and Marfurt (1999). The automated fracture detection flow used by Tomaso et al. (2013) and adapted by Bulhões et al. (2019), represented in Figure 6, has signal processing technology and interactive tools to decrease interpretation time compared to fully manual methods.

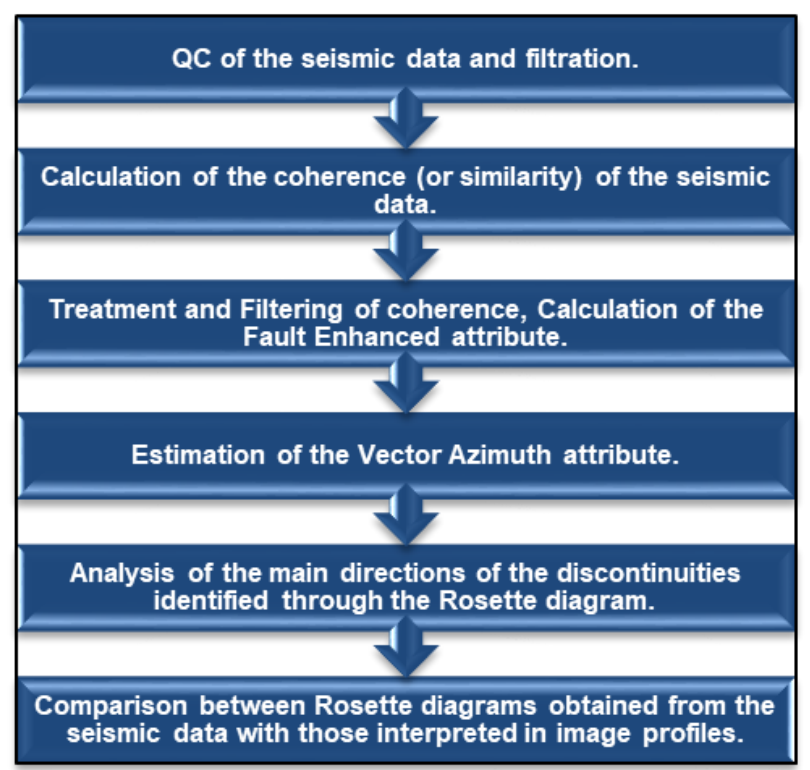

Figure 6: Workflow of automatic detection of faults and fractures using seismic attributes.

The flow input is a volume of discontinuity or similarity extracted from the amplitude, and the output is a volume of the relative probability of faults and fractures. The flow was applied to the $2 \mathrm{D}$ walkaway seismic.

The steps in the proposed workflow are:

1) preconditioning of the data for noise removal;

2) generation of unconventional geometric seismic attributes from an automatic fault extraction process;

3) principal component analysis in a multi-attribute approach as an input to a seismic pattern recognition 
process using filters structurally oriented by dip and azimuth volumes to highlight the discontinuities;

4) generation of an attribute that represents the vectors of the directions of faults and fractures extracted in each slice and determines the orientation of the azimuths of the families of fractures.

Vector Azimuth is the main product of this workflow. It is an attribute that represents fault and fracture's directions extracted in each slice from the preconditioned coherence attribute (Tomaso et al., 2013) and helps to determine the azimuths of fracture families. It contributes to the structural definition and consequently the understanding of orientation, geometry and fault network. compartmentalization of the reservoir and design of fractured zones, assisting in the identification of fracture families (sets) and studies of the occurrence of higher intensity zones fracture.

The result is compared to interpretations previously performed in the walkaround survey in the ratio data of the $T / R$ energies of the $S$-wave as a function of the azimuth, where a lower $T / R$ ratio is indicative of the presence of fracture runners (Daley et al., 1996, Horne 2003 \& Jocker et al. 2008) and with the interpretations made in the image profile.

The VSP walkaround survey was carried out with 16 sources located every $12^{\circ}$, covering $200^{\circ}$. The circular geometry has a radius of $2.3 \mathrm{~km}$. The descending compression waves could reach the subsurface's objective with incidence angles between $40^{\circ}$ and $50^{\circ}$, guaranteeing the generation of $S$ waves of great amplitude compared to noise.

The VSP attribute of the T / $R$ amplitude rate highlights a clear fracture pattern with faster shear waves over $108^{\circ}$ $\mathrm{N}$ (Figure 7).

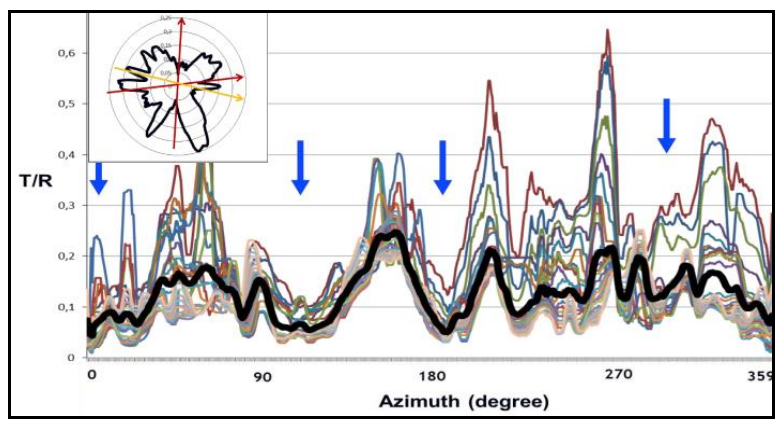

Figure 7: Ratio of $T / R$ energy of the $S$ wave as a function of the azimuth of the walkaround survey. Arrows where fracture corridors occur.

The acquisition geometry acquired for four walkaway seismic lines where the flow is applied, is in Figure 8 . The azimuths of the four lines are: Line 1 with $123^{\circ}$ azimuth, Line 2 with $71^{\circ}$ azimuth, Line 3 with $33^{\circ}$ azimuth and Line 4 with $13^{\circ}$ azimuth.

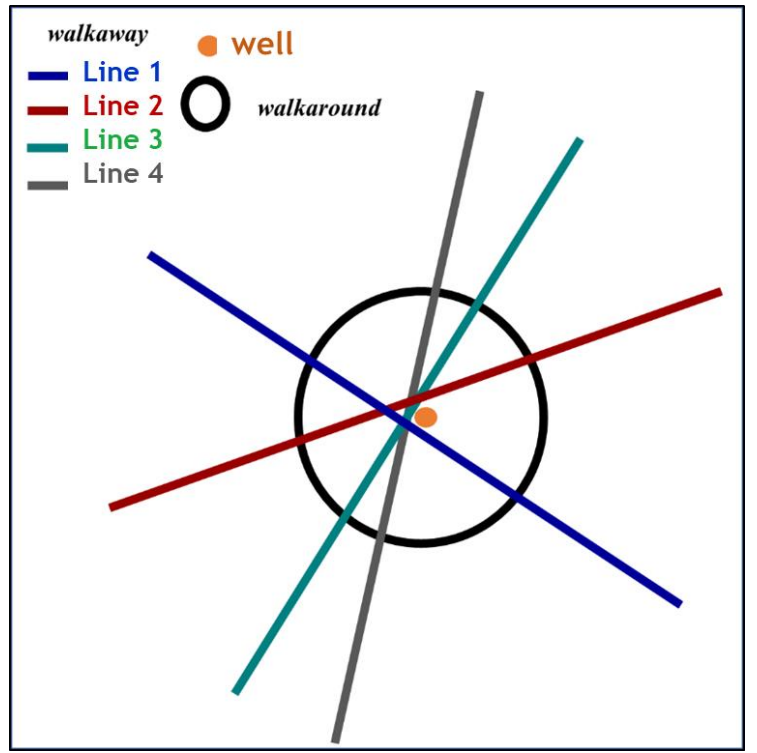

Figure 8: Geometry of walkaway (4 lines), walkaround (circular) and well (orange dot) surveys. VSP walkaway surveys in $122^{\circ} \mathrm{N}$ (Line 1), $71^{\circ} N$ (Line 2), $33^{\circ} N$ (Line 3) and $13^{\circ}$ (Line 4) directions

The interpretations performed in the image of the well were used to evaluate the result obtained in the flow of detection of faults and fractures. The profile interpreted with the respective rosette is in Figure 9. Two main directions stand out at $5^{\circ} \mathrm{N}$ and $85^{\circ} \mathrm{N}$.

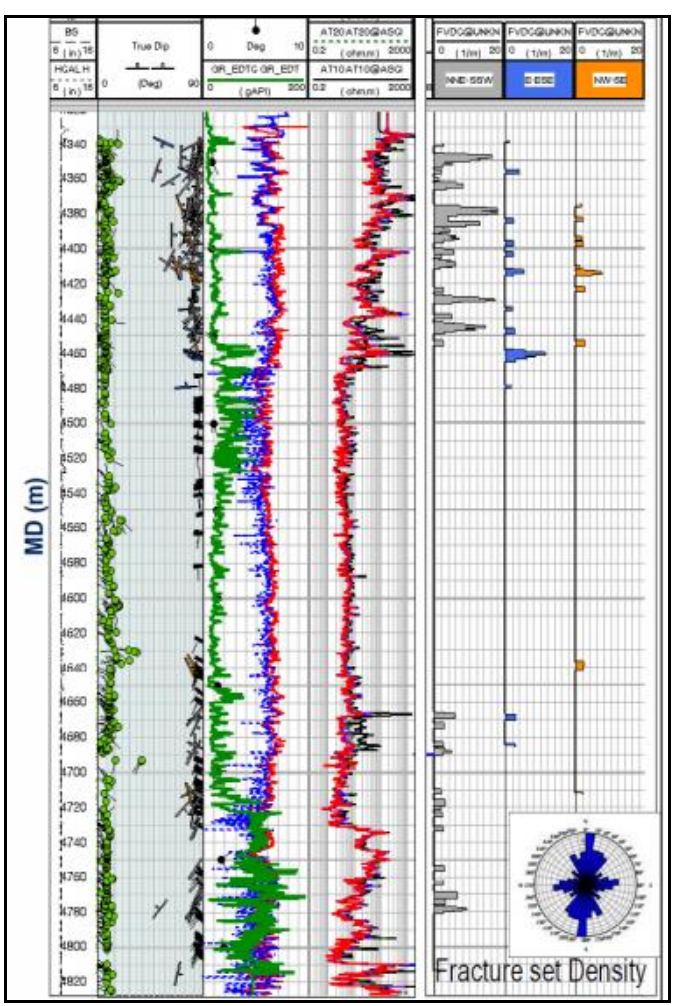

Figure 9: Profiles with faults and fractures interpreted from the image profile. The tracks represent the dip and azimuth and the density of the fracture set. The main interpreted directions are represented in the rosette diagram. 


\section{Results}

Figure 10 shows a migrated seismic section (PSDM in depth domain) for the Line 3 walkaway (Figure 10a), the corresponding coherence attribute (Figure 10b), and the result of the proposed workflow to highlight faults and fractures (Figure 10c).

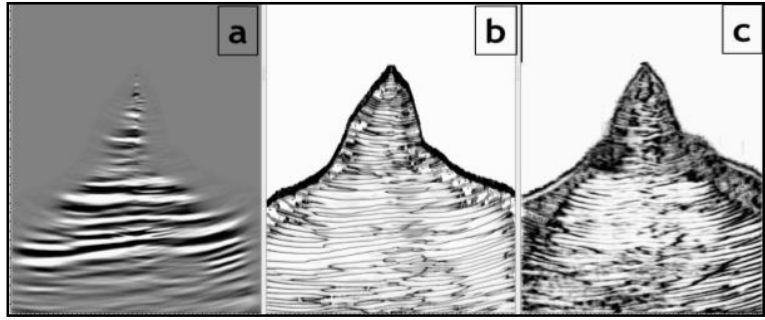

Figure 10: (a) Line 3 of the walkaway survey with anisotropic PSDM processing (b) coherence attribute and (c) fault enhanced attribute.

Lines 1, 2 and 4 were processed with the same parameters as Line 3 and the last step generated Vector Azimuth that paints each fault/fracture with a color representing its azimuth over a purple background. Figure 11 shows the rosette diagrams of the main directions identified by the automated detection workflow in each line.

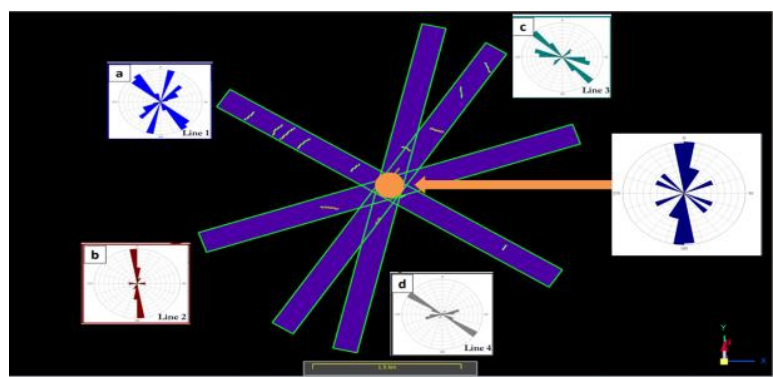

Figure 11: Rosette diagrams with the discontinuity directions detected by the automated flow applied to the walkaway survey lines.

At the intersection of the four walkaway lines, a rosette diagram was generated to represent the main fault directions identified at well's position (Figure 12a). The main direction identified in the flow was $5^{\circ} \mathrm{N}$, showing a strong similarity with those interpreted in walkaround's data (Figure 12b) and image profile (Figure 12c). The secondary directions identified showed a lower correlation.

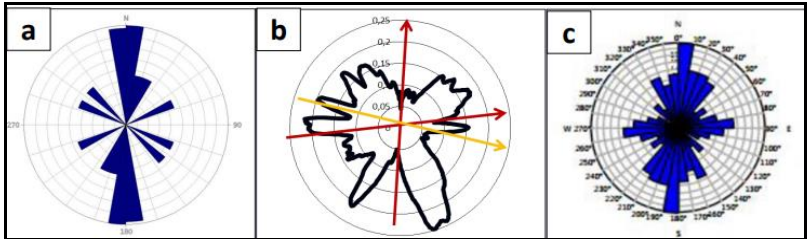

Figure 12: (a) Rosette diagrams of the fractures detected using the automated flow in the seismic data walkaway, (b) $T / R$ ratio of the S-wave energy of the VSP walkaround $T / R$ and (c) the rosette with the faults and fractures interpreted in the image profile.

\section{Conclusions}

The directions of faults and fractures detected from the walkaway seismic using the automatic flow showed a great visual correlation in the main directions compared to the interpretations in the well image and walkaround profile. The attributes proved to be quite effective in the identification and improve the visualization of faults and fractures.

The best fault identification allows the construction of a more realistic structural model, outlining the fracturing patterns and indicating changes in the stress field throughout the geological history of a sedimentary basin, contributing to reducing exploratory risk and delimitation reservoirs in 3D surveys.

\section{Acknowledgments}

The authors would like to thank Petrobras, the manager Francisco Aquino and Leonardo Matriciano for their support in publishing the work.

\section{References}

AZEVEDO, L. E PEREIRA, G. R. 2009. Seismic attributes in hydrocarbon reservoirs characterization. Universidade de Aveiro: Dissertação de Mestrado.

BAIRD, A.F., KENDALL, J., e ANGUS, D., 2013. Frequency-dependent seismic anisotropy due to fractures: Fluid flow versus scattering.

BULHÕES, F. C., FERREIRA, G. D. e OLIVEIRA, R. L. 2019. Detecção de Falhas e Fraturas Automatizada em Dados de Sísmica de Poço na Bacia De Campos. Anais do II Simpósio Brasileiro de Geologia e Geofísica Marinha. PGGM.

CAMPBELL A., FRYER, A., WAKEMAN, S. 2005, Vertical seismic profiles more than just a corridor stack. The Leading Edge, July, P. 694-697

DALEY, T. M., LEONARD, M., MAJER, E.L., QUEEN, H., and COX, V.D. 1996. Measurement of Fracture-Induced Anisotropy in Shear-Wave Attenuation and Velocity from VSP Data. Ernest Orlando Lawrence Berkeley National Laboratory. October 1996.

DORN, G. A., JAMES, H. E., EVINS, L. 2005. Automatic Fault Extraction (AFE) in 3D Seismic Data. Anais da 2005 CSEG Nationonal Convention.

GERSZTENKORN, A. and MARFURT, K. J. 1999 Eigenstructure-based coherence computations as an aid to 3-D structural and stratigraphic mapping. Geophysics 64(5):1468-1479.

HALE, D., and EMANUEL, J. 2002. Atomic meshing of seismic images. Anais do 72th Annual International Meeting, SEG. p. 2126-2129.

HORNE, S. A., SLATER, C. P., MALEK, S. A. HILL, A. e WIJNANDS, F. 2003. Walkaround VSPs for fractured reservoir characterization. Anais da SEG 2000 Expanded Abstracts

HORNE, S. 2003. Fracture characterization from walkaround VSPs. Geophysical Prospecting, 51, 493499.

JOCKER, J.,PRIOUL, R., MONTAGGIONI, P., IDREES, M., LOUBENS, E., and ESCAR'E, L. 2008. Analysis of 
walkaround VSP azimuthal response using borehole images. Anais do SEG Las Vegas 2008 Annual Meeting

LIRA, J. E. M., SANTOS, R. A., BULHÕES, F. C., FERREIRA, G. D., TANAKA, A., CARVALHO, J. G., BARRETO, A. C. 2018. Detecção de Falhas e Fraturas em Reservatórios de Baixa Permeabilidade Utilizando Atributos Geométricos. Anais do VIII Simpósio Brasileiro de Geofísica, Salinópolis. SBGf.

MARFURT, K., KWIATKOWSKI, T. e MATOS, M. 2011. Attribute-Assisted Seismic Processing and Interpretation AASPI.

PEDERSEN, S., SKOV, T., HETLELID, A., FAYEMENDY, P. RANDEN, T. and SONNELAND, L. 2003. New paradigm of fault interpretation, Anais do 73nd Annual International Meeting, SEG.

PRIOUL, R. and JOCKER, J. 2009. Fracture characterization at multiple scales using borehole images, sonic logs, and walkaround vertical seismic profile. AAPG Bulletin 93(11): 1503-1516.

QUEEN, J. H. and RIZER, W. D. 1990. An Integrated Study of Seismic Anisotropy and the Natural Fracture System at the Conoco Borehole Test Facility, Kay County, Oklahoma. Journal of Geophysical Research, 95, B7:11,255-273

SANTOSH, D., ADITI, B., POONAM, K., PRIYANKA S., RAO P.H, HASAN, S. Z., e HARINARAYANA, T. 2013. An Integrated approach for faults and fractures delineation with dip and curvature attributes. Anais da10th Biennial International Conference \& Exposition.

TOMASO, K., BENAC, P., SARTURI, J., GONZÁLEZ, G. and DE RIBET, B. 2013. Seismic fracture characterization workflow and support for the geological model: Albian carbonate reservoir, Campos Basin, Brazil. Anais do 13th International Congress of the Brazilian Geophysical Society realizado no Rio de Janeiro, Brasil. 